\title{
Efeito de épocas de colheita e período de repouso pós-colheita sobre as características físicas de frutos e sementes de mamoneira ${ }^{1}$
}

\author{
Harvest periods and post-harvest resting period over physics \\ characteristics of fruits and seeds in castor bean
}

\author{
Líbia Belisário da Silva²; Cibele Chalita Martins ${ }^{3}$
}

\section{Resumo}

O presente trabalho teve como objetivo avaliar o efeito dos períodos de colheita e o repouso pós-colheita sobre as características físicas de frutos e sementes de mamoneira (cultivar AL Guarany 2002) e verificar se estas características podem ser utilizadas na identificação do ponto ideal de colheita. Foram avaliadas nove épocas de colheita dos racemos, no período de 30 até 142 dias após a antese (DAA), em intervalos de 14 dias e quatro condições de repouso: sem e com repouso de sete dias de sementes extraídas (nuas), de frutos e de frutos presos ao racemo. O teor de água e a espessura das sementes, o comprimento, largura e peso fresco dos frutos e sementes e a emergência de plântulas em areia foram avaliados em um delineamento inteiramente casualisado, com quatro repetições. Concluiu-se que os períodos de colheita e de repouso pós-colheita afetaram as características físicas de frutos e sementes de mamoneira, mas nenhuma dessas características foi alterada de forma significativa por ocasião da maior porcentagem de emergência de plântulas, não podendo ser utilizada para a identificação do ponto ideal de colheita.

Palavras-chave: Fenologia, maturação, Ricinus communis. AL Guarany 2002

\begin{abstract}
This study aimed to assess the effect of harvesting times and of post-harvest resting period on physical characteristics of fruits and seeds of castor bean (AL Guarany 2002 genotype) and to verify if theses characteristics could be used to identify the ideal harvest time. Nine times of raceme harvest were assessed from 30 to the 142 days after anthesis (DAA) at fourteen days intervals, and four conditions of resting; (without and with seven days of resting period of seeds extracted (bare), from fruits and fixed to the racemes). It was evaluated water content, seed thickness, and length, width, and weight of fresh fruits and seeds, and seedling emergence in sand. The statistical design was completely randomized with four replications. The harvest times and the post-harvest rest period affected the physical characteristics of fruits and seeds of castor bean but none of these have proved to be effective in the identification of the ideal harvest time.
\end{abstract}

Key words: Phenology, maturation, Ricinus communis, AL Guarany 2002

1 Parte da Dissertação de Mestrado em Agronomia, apresentado pela primeira autora.

2 Eng ${ }^{\mathrm{a}}$. Agra . Mestranda em Produção e Tecnologia de Sementes - FCA/UNESP; E-mail: libiabel@yahoo.com.br.

Prof ${ }^{a}$ Dr $^{\text {a }}$ Depto. de Agricultura/Melhoramento Vegetal, FCA/UNESP.

Autor para correspondência 


\section{Introdução}

A cultura da mamona (Ricinus communis L.) expandiu-se em vários estados do Brasil, devido a sua utilização para a síntese de biodiesel, promovendo uma demanda por sementes. Assim, as pesquisas na área de produção de sementes de mamona justificam-se pela necessidade de qualidade do produto, escassez de informações referentes à tecnologia de produção, aumento da área plantada e potencialidade da espécie (SAVY FILHO, 2005; OLIVEIRA et al., 2006).

Na maior parte da área plantada com mamoneira no Estado de São Paulo, são utilizadas cultivares indeiscentes, destacando-se a AL Guarany 2002, desenvolvida pelo Departamento de Sementes, Mudas e Matrizes da Coordenadoria de Assistência Técnica Integral, da Secretaria da Agricultura e Abastecimento do Estado de São Paulo. Essa cultivar apresenta como características: altura de 1,6 a 2,6 m, caule de coloração roxo-avermelhado, com cerosidade, fruto indeiscente e com espinhos, folha afunilada e ciclo médio de 180 dias. O peso médio de 1.000 sementes é de $460 \mathrm{~g}$, o teor de óleo da semente situa-se entre 47 e $48 \%$ e a produtividade média de grãos é de 1.000 a 2.000 kg/ha (AMARAL, 2007).

Para a cultura da mamona, a colheita manual é indicada para pequenas e médias propriedades, onde há disponibilidade de mão-de-obra. Consiste em se quebrar ou cortar os cachos pela base, utilizandose faca, canivete, tesoura ou podão. Quando a produção de mamona é maior que a capacidade de secagem, devido à área do terreiro, recomenda-se efetuar, na lavoura, o desprendimento dos frutos, para evitar o transporte de um grande volume de material vegetal desnecessário. Para isto, devese usar pentes feitos de prego sem cabeça ou de pinos de ferro colocados na parte interna superior do depósito, de forma que o cacho seja passado por entre os dentes do pente, de baixo para cima, de modo que os frutos se desprendam e caiam dentro do recipiente de transporte (SILVA, 2007).
Tanto no sistema de colheita de cachos inteiros como no de frutos soltos, o material é recolhido em cestos, carroças ou reboques e transportados para um período de repouso, num terreiro para secagem (SAVY FILHO, 2005).

Em espécies que apresentam o florescimento contínuo como a mamoneira, a colheita seguida de um período de repouso dos frutos pode trazer vantagens, pois esses frutos apresentam desuniformidade nos períodos de maturação e o repouso permitiria que os frutos imaturos completassem o processo. Dessa forma, um número menor de colheitas poderia ser praticado colhendo-se frutos em períodos de desenvolvimento distintos, mas próximos da maturidade fisiológica (quando a semente apresenta máxima germinação e vigor). Esse procedimento torna possível a colheita de frutos imaturos, mas com a obtenção de sementes de alta qualidade, desde que as sementes permaneçam dentro do fruto, antes de sua extração (CASTRO; GODOY; CARDOSO, 2008). Em alguns casos, essas sementes são capazes de absorver parte das reservas acumuladas nos frutos durante o repouso, completando o processo de maturação (AROUCHA et al., 2005; COSTA; CARMONA; NASCIMENTO, 2006; CASTRO; GODOY; CARDOSO, 2008).

A maturação das sementes é acompanhada por visíveis mudanças no aspecto externo dos frutos e das sementes que podem ser utilizados como um índice para a identificação do ponto de colheita na maturidade fisiológica (AGUIAR; PERENCIN; KAGEYAMA, 1988; BARBOSA et al., 1992; FIGLIOLIA; PIÑA-RODRIGUES, 1995; FOWLER; MARTINS, 2001; CASTRO; GODOY; CARDOSO, 2008). Deste modo, uma determinada característica de fácil identificação, como tamanho, cor, peso ou teor de água, pode ser utilizada para que as sementes sejam colhidas quando apresentam máxima germinação e vigor (CARVALHO; NAKAGAWA, 2000). Este seria o ponto ideal de colheita. Contudo, a eficiência e facilidade de aplicação desta metodologia depende da espécie e do melhoramento genético à que a 
planta foi submetida, pois as variedades costumam ser mais desuniformes que os híbridos, quanto à maturação e característica físicas das sementes e frutos (CARVALHO; NAKAGAWA, 2000; SILVA, 2007; BAHIA et al., 2008).

Durante o processo de maturação no campo, as sementes crescem rapidamente, atingindo $o$ tamanho máximo num período de tempo curto, devido à multiplicação e desenvolvimento das células que constituem o eixo embrionário e o tecido de reserva. O tamanho é mantido por certo tempo, mas ao final do período de maturação apresenta leve redução, devido à perda de água (CARVALHO; NAKAGAWA, 2000). Para algumas espécies, como Glycine max (L.) Merrill, Torresia acreana Ducke, Mimosa caesalpiniifolia Benth., e Tibouchina granulosa Cogn. o tamanho do fruto pode ser usado para a determinação do momento ideal de colheita, (CROOKSTON; HILL, 1978; FIRMINO; SANTOS; SANTOS FILHO, 1996; ALVES et al., 2005; LOPES; DIAS; PEREIRA, 2005). Para Santos Neto et al. (2006), a identificação de características físicas de sementes de mamoneira, correlacionadas com a qualidade fisiológica, permite a eliminação de sementes indesejáveis, possibilitando o aprimoramento da qualidade dos lotes.

O presente trabalho teve como objetivo avaliar o efeito dos períodos de colheita e do repouso póscolheita sobre as características físicas de frutos e sementes de mamoneira e se estas características podem ser utilizadas na identificação do ponto ideal de colheita.

\section{Material e métodos}

O experimento, foi conduzido em condições de campo, emárea experimental pertencenteà Faculdade de Ciências Agronômicas da UNESP, Campus de Botucatu, em NITOSSOLO VERMELHO ESTRUTURADO (EMPRESA BRASILEIRA DE PESQUISA AGROPECUÁRIA, 1999). O campo experimental foi instalado em área uniforme de $1.638 \mathrm{~m}^{2}$ e no preparo do mesmo utilizou-se o sistema convencional, constando de uma aração e duas gradagens. A semeadura foi realizada no dia 21 de novembro de 2005, com espaçamento entre linhas de $1,8 \mathrm{~m}$ e densidade de uma planta por metro. A adubação foi calculada tomandose como base os resultados da análise química de solo, cuja amostragem foi feita antes do preparo da área. A cultura recebeu todos os tratos culturais $\mathrm{e}$ fitossanitários (desbaste, capinas e aplicação de defensivos). Para o estudo da maturidade fisiológicas das sementes, as flores foram etiquetadas na antese, entre 10 de janeiro a 3 de fevereiro de 2006 com visitas diárias ao campo.

A colheita dos racemos foi realizada manualmente, com auxílio de tesoura de poda, . coletando-se sempre o primeiro racemo, dos 30 até 142 dias após a antese (DAA), em intervalos de 14 dias, totalizando nove épocas de colheita. A primeira época de colheita ocorreu no dia 20 de fevereiro de 2006 e a última no dia cinco de junho de 2006.

Para cada época de colheita foram obtidos 30 racemos, divididos em três partes iguais de 10 racemos. A primeira parte teve as sementes extraídas dos frutos, a segunda parte teve os frutos removidos dos racemos e, na terceira parte, os racemos foram mantidos intactos. Os frutos foram avaliados quanto às características físicas. Metade das sementes extraídas (nuas) foram imediantamente encaminhadas ao Laboratório de Análise de Sementes do Departamento de Produção Vegetal da Faculdade de Ciências Agronômicas da UNESP, para a avaliação da qualidade e a outra metade junto com os frutos soltos e os frutos presos aos racemos foram colocados em repouso por sete dias em peneiras, em cima de balcões expostos à sombra. Após o repouso, os frutos foram novamente avaliados quanto às características físicas e as sementes foram extraídas dos frutos e também encaminhadas ao laboratório, onde foram feitas as determinações das características físicas das sementes e a avaliação da porcentagem de emergência de plântulas.

Características físicas dos frutos - foram mensurados o comprimento e a largura dos frutos 
com o auxílio de um paquímetro utilizando-se quatro repetições de 20 frutos. O peso fresco foi determinado em balança analítica com precisão de $0,001 \mathrm{~g}$ em quatro repetições de 20 frutos.

Características físicas das sementes comprimento, largura e espessura das sementes foram mensurados com o auxílio de um paquímetro, e o peso fresco foi determinado em balança analítica com precisão de 0,001g. Essas características foram avaliadas utilizando-se quatro repetições de 20 sementes. O teor de água das sementes foi determinado utilizando-se quatro repetições de 10 sementes por tratamento pelo método da estufa a $105^{\circ} \pm 3^{\circ} \mathrm{C}$, por 24 horas (BRASIL, 1992).

Teste de emergência de plântulas - teste realizado sob temperatura constante de $30^{\circ} \mathrm{C}$ e luz (78 $\left.\mu \mathrm{mol} . \mathrm{s}^{-1} \cdot \mathrm{m}^{-2} / 8 \mathrm{~h}\right)$. Foram semeadas oito subamostras de 10 sementes entre areia esterilizada e umedecida com água destilada na proporção de $50 \%$ da capacidade de retenção da areia em água (BRASIL, 1992), dentro de caixas plásticas transparentes $(110 \times 110 \times 35 \mathrm{~mm})$ colocadas dentro de saco plástico para a manutenção da umidade. A contagem das plântulas emersas foi realizada aos 28 dias após a semeadura.

Os dados foram submetidos a análise de variância em delineamento inteiramente casualizado, com quatro repetições, em arranjo fatorial 9x3 para frutos, onde nove foram às épocas de colheita e três as condições de repouso pós-colheita e em arranjo fatorial 9x4 para sementes, onde nove foram as épocas de colheita e quatro as condições de repouso pós-colheita. As médias foram comparadas pelo teste de Tukey a $5 \%$ de probabilidade. Os dados em porcentagem foram transformados em $(x+0,5)^{1 / 2}$ previamente à análise e as médias apresentadas são dos valores originais. O programa estatístico utilizado foi o SISVAR.

\section{Resultados e discussão}

O comprimento e a largura dos frutos sem repouso nas duas primeiras colheitas, aos 30 e
44 dias após a antese, foram máximos, havendo redução significativa aos 58 dias e que acentuouse aos 72 dias, mantendo-se relativamente estável a partir desta época de colheita para a largura e com oscilações pequenas para o comprimento dos frutos (Tabela 1).

Pequenas variações dos resultados podem ser atribuídas à dificuldade na obtenção de amostras uniformes entre as épocas de colheita devido ao fato da mamoneira apresentar frutos e sementes com certa heterogeneidade de tamanho e maturação dentro do mesmo racemo, que é uma característica inerente à esta variedade, menos melhorada geneticamente que um híbrido da mesma espécie (BAHIA et al., 2008). De modo similar, para plantas de eucalipto o tamanho dos frutos não se revelou, também, um bom índice de maturação de sementes, por causa da grande variação existente entre os frutos das árvores matrizes (AGUIAR; PERECIN; KAGEYAMA, 1988).

O tamanho dos frutos também não foi eficiente para a determinação do ponto de maturidade fisiológica das sementes de copaíba (Copaifera langsdorffii Desf), tarumã-de-espinho (Citharexylum montevidense Spreng) e sabiá (Mimosa caesalpiniifolia Benth.) (BARBOSA et al., 1992; LEONHARDT et al., 2001; ALVES et al., 2005).

Aos 100 dias após a antese, verificou-se a deiscência de parte dos frutos de mamoneira cultivar AL Guarany 2002 com dispersão das sementes e a queda de frutos secos do racemo. Assim, a partir desta época de colheita, as determinações foram realizadas amostrando-se no campo os racemos mais íntegros possível, o que também pode ter causado variações indesejadas no experimento.

Nas condições de repouso, a redução do comprimento com o avanço da época de colheita, não foi tão evidente se comparado aos frutos sem repouso, devido talvez ao menor comprimento nas épocas iniciais de colheita dos frutos. Isto pode ser explicado pela desidratação dos frutos submetidos ao repouso, verificado pelo peso fresco até 58 dias 
após a antese. Nos frutos em repouso, a largura aumentou com o avanço das épocas de colheita, apresentando valores máximos aos 58 dias. Nas épocas de colheita seguintes houve diminuição da largura dos frutos em repouso para valores estatisticamente similares aos apresentados aos 30 dias. Para frutos em repouso e presos ao racemo, a largura foi mantida dos 58 dias até a época final, aos 142 dias, embora tenham sido verificadas oscilações nos valores aos 114 dias (Tabela 1).

Tabela 1. Comprimento, largura e peso fresco de frutos de mamoneira colhidos em diferentes épocas (E) e submetidos a condições de repouso pós-colheita (R). Botucatu-SP, 2007.

\begin{tabular}{|c|c|c|c|c|c|c|c|}
\hline \multirow{2}{*}{$\begin{array}{l}\text { Parâmetros } \\
\text { dos frutos }\end{array}$} & \multirow{2}{*}{$\begin{array}{l}\text { Épocas de colheita } \\
\text { (E) DAA }\end{array}$} & \multirow{2}{*}{\multicolumn{2}{|c|}{ Sem repouso }} & \multicolumn{4}{|c|}{ Condições de repouso (R) } \\
\hline & & & & \multicolumn{2}{|c|}{ Fruto } & \multicolumn{2}{|r|}{ Racemo } \\
\hline \multirow{9}{*}{ Comprimento $(\mathrm{cm})$} & 30 & 2,23 & $\mathrm{aA}$ & 1,92 & $\mathrm{aB}$ & 1,96 & $\mathrm{aB}$ \\
\hline & 44 & 2,21 & $\mathrm{aA}$ & 1,93 & $\mathrm{aB}$ & 1,95 & $\mathrm{abB}$ \\
\hline & 58 & 2,06 & $\mathrm{bA}$ & 1,88 & $\mathrm{abB}$ & 1,92 & abcB \\
\hline & 72 & 1,94 & $\operatorname{cdA}$ & 1,91 & $\mathrm{abA}$ & 1,94 & $\mathrm{abA}$ \\
\hline & 86 & 1,80 & $\mathrm{eB}$ & 1,84 & $\mathrm{bAB}$ & 1,86 & $\mathrm{cA}$ \\
\hline & 100 & 1,96 & $\mathrm{cA}$ & 1,90 & $\mathrm{abB}$ & 1,91 & $a b c B$ \\
\hline & 114 & 1,92 & $\operatorname{cdA}$ & 1,86 & $\mathrm{abB}$ & 1,85 & $\mathrm{cB}$ \\
\hline & 128 & 1,88 & $\mathrm{dA}$ & 1,88 & $\mathrm{abA}$ & 1,88 & $\mathrm{bcA}$ \\
\hline & 142 & 1,89 & $\mathrm{cdA}$ & 1,83 & $\mathrm{bB}$ & 1,86 & $\mathrm{cAB}$ \\
\hline DMS (E d. R) & & \multicolumn{6}{|c|}{0,07} \\
\hline DMS (R d. E) & & \multicolumn{6}{|c|}{0,05} \\
\hline C.V. $(\%)$ & & \multicolumn{6}{|c|}{1,69} \\
\hline \multirow{9}{*}{ Largura $(\mathrm{cm})$} & 30 & 2,04 & $\mathrm{aA}$ & 1,66 & $\mathrm{bcB}$ & 1,64 & $\mathrm{bcB}$ \\
\hline & 44 & 2,05 & $\mathrm{aA}$ & 1,64 & $\mathrm{cB}$ & 1,69 & $a b c B$ \\
\hline & 58 & 1,86 & $\mathrm{bA}$ & 1,75 & $\mathrm{aB}$ & 1,73 & $\mathrm{aB}$ \\
\hline & 72 & 1,74 & $\mathrm{cA}$ & 1,72 & $\mathrm{abA}$ & 1,71 & abcA \\
\hline & 86 & 1,67 & $\mathrm{cA}$ & 1,68 & $\mathrm{abcA}$ & 1,72 & $\mathrm{abA}$ \\
\hline & 100 & 1,74 & $\mathrm{cA}$ & 1,68 & $\mathrm{abcAB}$ & 1,67 & abcB \\
\hline & 114 & 1,72 & $\mathrm{cA}$ & 1,63 & $\mathrm{cB}$ & 1,64 & $\mathrm{cB}$ \\
\hline & 128 & 1,71 & $\mathrm{cA}$ & 1,67 & $\mathrm{bcA}$ & 1,72 & $\mathrm{abA}$ \\
\hline & 142 & 1,71 & $\mathrm{cA}$ & 1,66 & $\mathrm{bcA}$ & 1,71 & $a b c A$ \\
\hline $\mathrm{DMS}(\mathrm{E}$ d. R) & & \multicolumn{6}{|c|}{0,07} \\
\hline DMS (R d. E) & & \multicolumn{6}{|c|}{0,05} \\
\hline C.V.(\%) & & \multicolumn{6}{|c|}{1,88} \\
\hline \multirow{9}{*}{ Peso fresco $(\mathrm{g})$} & 30 & 101,0 & $\mathrm{aA}$ & 15,0 & $\mathrm{~dB}$ & 16,0 & $\mathrm{~dB}$ \\
\hline & 44 & 105,2 & $\mathrm{aA}$ & 27,7 & $\mathrm{cB}$ & 31,5 & $\mathrm{bcB}$ \\
\hline & 58 & 75,7 & $\mathrm{bA}$ & 36,0 & $\mathrm{aB}$ & 39,7 & $\mathrm{aB}$ \\
\hline & 72 & 32,7 & $\mathrm{dA}$ & 34,7 & $\mathrm{abA}$ & 36,5 & $\mathrm{abA}$ \\
\hline & 86 & 33,7 & $\operatorname{cdA}$ & 30,7 & $\mathrm{bcA}$ & 31,5 & $\mathrm{bcA}$ \\
\hline & 100 & 38,5 & $\mathrm{cA}$ & 26,2 & $\mathrm{cC}$ & 32,0 & $\mathrm{bcB}$ \\
\hline & 114 & 35,0 & $\operatorname{cdA}$ & 31,0 & $a b c B$ & 27,5 & $\mathrm{cB}$ \\
\hline & 128 & 33,2 & $\mathrm{dA}$ & 26,0 & $\mathrm{cB}$ & 32,7 & $\mathrm{bA}$ \\
\hline & 142 & 31,7 & $\mathrm{dA}$ & 26,0 & $\mathrm{cB}$ & 31,7 & $\mathrm{bcA}$ \\
\hline $\mathrm{DMS}(\mathrm{E} \mathrm{d} . \mathrm{R})$ & & \multicolumn{6}{|c|}{5,11} \\
\hline DMS (R d. E) & & \multicolumn{6}{|c|}{3,83} \\
\hline C.V.(\%) & & \multicolumn{6}{|c|}{6,01} \\
\hline
\end{tabular}

Médias seguidas das mesmas letras, maiúsculas para linha e minúsculas para coluna, não diferem entre si, pelo teste de Tukey a 1\% de probabilidade. DAA - dias após a antese 
O peso fresco dos frutos sem repouso apresentou valores máximos aos 30 e 44 dias após a antese, diminuindo aos 58 dias e reduzindo ainda mais aos 72 dias; a partir desta época manteve-se relativamente estável com pequenas oscilações. Essas reduções do peso fresco do fruto podem ser atribuídas ao processo natural de desidratação que ocorre durante a maturação (CARVALHO; NAKAGAWA, 2000). Contrariamente, o peso dos frutos com repouso, preso ou não ao racemo, apresentou os menores valores nas primeiras épocas de colheita, quando ainda imaturos, provavelmente pela secagem ocorrida durante o repouso associada ao baixo acúmulo de matéria seca nas sementes, de modo similar ao verificado em outros trabalhos sobre a maturação de sementes (ALVES et al., 2005; AROUCHA et al., 2005; COSTA; CARMONA; NASCIMENTO, 2006; CASTRO; GODOY; CARDOSO, 2008).

$\mathrm{Na}$ Tabela 2, verifica-se que as sementes sem repouso apresentaram valores de comprimento e largura máximos aos 30 dias após a antese e mínimos aos 86 dias e, para largura, também aos 114 dias. $\mathrm{O}$ comprimento e a largura das sementes sem repouso foram intermediários nas demais épocas. Durante a maturação, as sementes atingem o tamanho máximo num curto período de tempo, devido à multiplicação celular e a formação das suas estruturas. O tamanho é mantido por certo tempo, mas no final do período de maturação apresenta leve redução, devido à perda de água (CARVALHO; NAKAGAWA, 2000; ALVES et al., 2005).

Nas condições de repouso, os valores máximos de comprimento foram obtidos aos 58 dias após a antese para sementes nuas e aos 72 dias para repouso do fruto e do fruto preso ao racemo. As sementes nuas em repouso, apresentaram máxima largura aos 72 e 100 dias após a antese; sementes no fruto de 58 a 72 dias, aos 100 dias e a partir de 128 dias. As sementes provenientes de frutos presos ao racemo apresentaram máxima largura aos 72 dias. Assim, a largura e o comprimento das sementes não podem ser considerados bons índices de maturação, por causa das oscilações de valores destes parâmetros nas diferentes épocas de colheita, de modo similar ao constatado para Mimosa caesalpiniifolia Benth. por Alves et al. (2005). O repouso da semente dentro do fruto solto ou no fruto preso ao racemo não alterou o comprimento e a largura das sementes na maioria das épocas de colheita, em comparação à semente nua.

Embora os valores de comprimento e largura tenham oscilado muito entre as épocas de colheita, para as sementes submetidas ao repouso, de forma geral, as colheitas realizadas a partir de 44 dias após a antese originaram sementes maiores. Para algumas espécies, os valores máximos de tamanho das sementes podem ser alcançados precocemente e não coincidirem com os maiores valores de germinação e vigor (BARBOSA et al., 1992; ALVES et al., 2005). Deste modo, o tamanho das sementes pode não constituir um bom índice de maturação, se utilizado de forma isolada, devendo estar associados a outros indicadores (FIGLIOLIA; PIÑA-RODRIGUES, 1995; ALVES et al., 2005).

A espessura das sementes sem repouso mantevese máxima até aos 44 dias após a antese, com certa estabilidade a partir dos 58 dias. $\mathrm{O}$ repouso não alterou a espessura das sementes de forma tão intensa nas diferentes épocas de colheita, principalmente a partir dos 58 dias após a antese e se comparada ao comprimento e largura.

O maior tamanho das sementes sem repouso, quanto ao comprimento, largura e espessura, nas épocas iniciais de colheita pode ser atribuído ao máximo teor de água apresentado nessas épocas (Tabelas 2 e 3). O peso fresco das sementes sem repouso apresentou valores máximos aos 44 dias após a antese, diminuiu aos 58 dias e reduziu ainda mais aos 72 dias, mantendo uma ligeira estabilidade com pequenas oscilações (Tabela 3 ). Essas reduções do peso fresco das sementes podem ser atribuídas igualmente ao processo natural de desidratação que ocorreu com os frutos durante a maturação (CARVALHO; NAKAGAWA, 2000). Nas condições de repouso, os pesos das sementes apresentaram os menores valores nas primeiras épocas de colheita; provavelmente por estarem imaturos, com pouco acúmulo de matéria seca e devido a secagem durante o repouso. 
Tabela 2. Comprimento, largura e espessura de sementes de mamoneira colhidas em diferentes épocas (E) e submetidos a condições de repouso pós-colheita (R). Botucatu-SP, 2007.

\begin{tabular}{|c|c|c|c|c|c|c|c|c|c|}
\hline \multirow{2}{*}{ Parâmetros das sementes } & \multirow{2}{*}{$\begin{array}{c}\text { Épocas de } \\
\text { colheita (E) DAA }\end{array}$} & \multirow{2}{*}{\multicolumn{2}{|c|}{$\begin{array}{l}\text { Sem } \\
\text { repouso }\end{array}$}} & \multicolumn{6}{|c|}{ Condições de repouso(R) } \\
\hline & & & & \multicolumn{2}{|c|}{ Nuas } & \multicolumn{2}{|c|}{ Fruto } & \multicolumn{2}{|c|}{ Racemo } \\
\hline \multirow{9}{*}{ Comprimento (cm) } & 30 & 1,95 & $\mathrm{aA}$ & 1,45 & $\mathrm{cB}$ & 1,38 & $\mathrm{dC}$ & 1,38 & $\mathrm{dC}$ \\
\hline & 44 & 1,64 & $\mathrm{bA}$ & 1,51 & $b B$ & 1,47 & $\mathrm{cB}$ & 1,49 & $\mathrm{bcB}$ \\
\hline & 58 & 1,64 & $\mathrm{bA}$ & 1,56 & $\mathrm{aB}$ & 1,50 & $\mathrm{abcC}$ & 1,49 & $\mathrm{bcC}$ \\
\hline & 72 & 1,52 & $\mathrm{cAB}$ & 1,50 & $\mathrm{bcC}$ & 1,54 & $\mathrm{aAB}$ & 1,56 & $\mathrm{aA}$ \\
\hline & 86 & 1,41 & $\mathrm{eC}$ & 1,49 & bcAB & 1,47 & $\mathrm{cB}$ & 1,51 & abcA \\
\hline & 100 & 1,55 & $\mathrm{cA}$ & 1,49 & $\mathrm{bcB}$ & 1,50 & $\mathrm{abcB}$ & 1,51 & $a b c A B$ \\
\hline & 114 & 1,46 & $\mathrm{dA}$ & 1,47 & $\mathrm{bcA}$ & 1,49 & $\mathrm{bcA}$ & 1,48 & $\mathrm{cA}$ \\
\hline & 128 & 1,51 & $\mathrm{cA}$ & 1,49 & $\mathrm{bcA}$ & 1,50 & abcA & 1,53 & $\mathrm{abA}$ \\
\hline & 142 & 1,56 & $\mathrm{cA}$ & 1,52 & $a b A B$ & 1,52 & $a b A B$ & 1,51 & $a b c B$ \\
\hline DMS (E d. R) & & \multicolumn{8}{|c|}{0,04} \\
\hline DMS (R d. E) & & \multicolumn{8}{|c|}{0,04} \\
\hline C.V.(\%) & & \multicolumn{8}{|c|}{6,5} \\
\hline \multirow{9}{*}{ Largura (cm) } & 30 & 1,00 & $\mathrm{aA}$ & 0,86 & $\mathrm{bB}$ & 0,85 & $\mathrm{bB}$ & 0,82 & $\mathrm{dC}$ \\
\hline & 44 & 0,91 & $\mathrm{bA}$ & 0,88 & $\mathrm{abC}$ & 0,88 & $\mathrm{abAB}$ & 0,90 & $\mathrm{bcAB}$ \\
\hline & 58 & 0,90 & $\mathrm{bA}$ & 0,89 & $\mathrm{abA}$ & 0,90 & $\mathrm{aA}$ & 0,88 & $\mathrm{bcA}$ \\
\hline & 72 & 0,90 & $\mathrm{bcB}$ & 0,90 & $\mathrm{aB}$ & 0,91 & $\mathrm{aAB}$ & 0,94 & $\mathrm{aA}$ \\
\hline & 86 & 0,87 & $\mathrm{cdB}$ & 0,88 & $\mathrm{abB}$ & 0,88 & $\mathrm{abB}$ & 0,91 & $\mathrm{abA}$ \\
\hline & 100 & 0,88 & bcdA & 0,90 & $\mathrm{aA}$ & 0,90 & $\mathrm{aA}$ & 0,90 & bcA \\
\hline & 114 & 0,86 & $\mathrm{dA}$ & 0,87 & $\mathrm{abA}$ & 0,86 & $\mathrm{bA}$ & 0,87 & $\mathrm{cA}$ \\
\hline & 128 & 0,91 & $\mathrm{bA}$ & 0,89 & $\mathrm{abA}$ & 0,91 & $\mathrm{aA}$ & 0,92 & $\mathrm{abA}$ \\
\hline & 142 & 0,89 & bcdA & 0,87 & $\mathrm{abA}$ & 0,89 & $\mathrm{aA}$ & 0,89 & $\mathrm{bcA}$ \\
\hline $\mathrm{DMS}(\mathrm{E} \mathrm{d} . \mathrm{R})$ & & \multicolumn{8}{|c|}{0,03} \\
\hline DMS (R d. E) & & \multicolumn{8}{|c|}{0,02} \\
\hline C.V.(\%) & & \multicolumn{8}{|c|}{7,6} \\
\hline \multirow{9}{*}{ Espessura $(\mathrm{cm})$} & 30 & 0,69 & $\mathrm{abA}$ & 0,60 & $\mathrm{bB}$ & 0,61 & $\mathrm{abB}$ & 0,57 & $\mathrm{bB}$ \\
\hline & 44 & 0,71 & $\mathrm{aA}$ & 0,61 & $\mathrm{bB}$ & 0,61 & $a b B$ & 0,60 & $a b B$ \\
\hline & 58 & 0,64 & $\mathrm{cA}$ & 0,63 & $\mathrm{bA}$ & 0,63 & $\mathrm{abA}$ & 0,64 & $\mathrm{aA}$ \\
\hline & 72 & 0,63 & $\mathrm{cA}$ & 0,64 & $\mathrm{abA}$ & 0,64 & $\mathrm{abA}$ & 0,65 & $\mathrm{aA}$ \\
\hline & 86 & 0,63 & $\mathrm{cA}$ & 0,64 & $\mathrm{abA}$ & 0,63 & $\mathrm{abA}$ & 0,64 & $\mathrm{aA}$ \\
\hline & 100 & 0,65 & $\mathrm{bcA}$ & 0,63 & bA & 0,64 & $\mathrm{abA}$ & 0,63 & $\mathrm{aA}$ \\
\hline & 114 & 0,62 & $\mathrm{cA}$ & 0,60 & $\mathrm{bA}$ & 0,59 & $\mathrm{bA}$ & 0,61 & $\mathrm{abA}$ \\
\hline & 128 & 0,64 & $\mathrm{cA}$ & 0,64 & $\mathrm{abA}$ & 0,65 & $\mathrm{aA}$ & 0,64 & $\mathrm{aA}$ \\
\hline & 142 & 0,63 & $\mathrm{cB}$ & 0,69 & $\mathrm{aA}$ & 0,63 & $a b B$ & 0,62 & $\mathrm{abB}$ \\
\hline $\mathrm{DMS}(\mathrm{E} \mathrm{d} . \mathrm{R})$ & & \multicolumn{8}{|c|}{0,05} \\
\hline DMS (R d. E) & & \multicolumn{8}{|c|}{0,04} \\
\hline C.V.(\%) & & \multicolumn{8}{|c|}{17,2} \\
\hline
\end{tabular}

Médias seguidas das mesmas letras, maiúsculas para linha e minúsculas para coluna, não diferem entre si, pelo teste de Tukey a 1\% de probabilidade. DAA - dias após a antese 
Tabela 3 - Peso fresco, teor de água e porcentagem de emergência de plântulas das sementes de mamoneira colhidas em diferentes épocas (E) e submetidas a condições de repouso pós-colheita (R). Botucatu-SP, 2007.

\begin{tabular}{|c|c|c|c|c|c|c|c|c|c|}
\hline \multirow{2}{*}{ Parâmetros das sementes } & \multirow{3}{*}{$\begin{array}{c}\text { Epocas de } \\
\text { colheita (E) } \\
\text { DAA } \\
30\end{array}$} & \multirow{2}{*}{\multicolumn{2}{|c|}{$\begin{array}{c}\text { Sem } \\
\text { repouso }\end{array}$}} & \multicolumn{6}{|c|}{ Condições de repouso (R) } \\
\hline & & & & \multicolumn{2}{|c|}{ Nuas } & \multicolumn{2}{|c|}{ Fruto } & \multicolumn{2}{|c|}{ Racemo } \\
\hline \multirow{9}{*}{ Peso fresco $(\mathrm{g})$} & & 0,52 & $\mathrm{bA}$ & 0,13 & $\mathrm{~dB}$ & 0,12 & $\mathrm{fB}$ & 0,12 & $\mathrm{eB}$ \\
\hline & 44 & 0,56 & $\mathrm{aA}$ & 0,32 & $\mathrm{cC}$ & 0,32 & $\mathrm{eC}$ & 0,35 & $\mathrm{~dB}$ \\
\hline & 58 & 0,52 & $\mathrm{bA}$ & 0,43 & $\mathrm{abB}$ & 0,39 & $\mathrm{dC}$ & 0,43 & $\mathrm{bB}$ \\
\hline & 72 & 0,42 & $\mathrm{eB}$ & 0,43 & $\mathrm{abB}$ & 0,46 & $\mathrm{aA}$ & 0,47 & $\mathrm{aA}$ \\
\hline & 86 & 0,44 & $\operatorname{deA}$ & 0,41 & $\mathrm{bBC}$ & 0,40 & $\mathrm{cdC}$ & 0,43 & $\mathrm{bAB}$ \\
\hline & 100 & 0,45 & cdeA & 0,45 & $\mathrm{aA}$ & 0,42 & $\mathrm{bcB}$ & 0,45 & $a b A B$ \\
\hline & 114 & 0,44 & deA & 0,44 & $\mathrm{abA}$ & 0,45 & $\mathrm{abA}$ & 0,44 & $\mathrm{bA}$ \\
\hline & 128 & 0,48 & $\mathrm{cA}$ & 0,43 & $a b B$ & 0,40 & $\mathrm{cdC}$ & 0,34 & $\mathrm{dD}$ \\
\hline & 142 & 0,47 & $\operatorname{cdA}$ & 0,44 & $\mathrm{aB}$ & 0,45 & $\mathrm{aAB}$ & 0,39 & $\mathrm{cC}$ \\
\hline DMS (E d. R) & & \multicolumn{8}{|c|}{0,03} \\
\hline DMS (R d. E) & & \multicolumn{8}{|c|}{0,02} \\
\hline C.V. $(\%)$ & & \multicolumn{8}{|c|}{15,8} \\
\hline \multirow{9}{*}{ Teor de água (\%) } & 30 & 81,9 & $\mathrm{aA}$ & 5,1 & $\mathrm{abB}$ & 5,9 & $\mathrm{abB}$ & 6,0 & abB \\
\hline & 44 & 44,0 & $\mathrm{bA}$ & 5,5 & $\mathrm{abB}$ & 6,0 & $\mathrm{aB}$ & 6,6 & $\mathrm{aB}$ \\
\hline & 58 & 24,1 & $\mathrm{cA}$ & 5,0 & $\mathrm{bB}$ & 5,7 & $a b B$ & 5,7 & $\mathrm{abB}$ \\
\hline & 72 & 11,5 & $\mathrm{dA}$ & 5,2 & $a b B$ & 5,3 & $\mathrm{bB}$ & 5,5 & $\mathrm{abB}$ \\
\hline & 86 & 11,1 & $\mathrm{dA}$ & 5,8 & $\mathrm{abB}$ & 5,7 & $\mathrm{abB}$ & 5,7 & $\mathrm{abB}$ \\
\hline & 100 & 7,9 & $\mathrm{dA}$ & 4,9 & $\mathrm{bB}$ & 5,3 & $\mathrm{bB}$ & 5,2 & $\mathrm{abB}$ \\
\hline & 114 & 6,6 & $\mathrm{dA}$ & 4,7 & $\mathrm{bB}$ & 5,1 & $\mathrm{bB}$ & 4,6 & $\mathrm{bB}$ \\
\hline & 128 & 10,2 & $\mathrm{dA}$ & 4,1 & $\mathrm{bB}$ & 5,0 & $\mathrm{bB}$ & 4,6 & $\mathrm{bB}$ \\
\hline & 142 & 8,4 & $\mathrm{dA}$ & 6,8 & $\mathrm{aA}$ & 5,7 & $\mathrm{abA}$ & 6,4 & $\mathrm{aA}$ \\
\hline $\mathrm{DMS}(\mathrm{E} \mathrm{d} . \mathrm{R})$ & & \multicolumn{8}{|c|}{0,75} \\
\hline DMS (R d. E) & & \multicolumn{8}{|c|}{0,62} \\
\hline C.V. $(\%)$ & & \multicolumn{8}{|c|}{11,8} \\
\hline \multirow{9}{*}{$\begin{array}{c}\text { Emergência } \\
\text { de plântulas (\%) }\end{array}$} & 30 & 0 & $\mathrm{cB}$ & 1 & $\mathrm{dAB}$ & 0 & $\mathrm{~dB}$ & 8 & $\mathrm{bA}$ \\
\hline & 44 & 1 & $\mathrm{cC}$ & 1 & $\mathrm{dC}$ & 29 & $\mathrm{cB}$ & 51 & $\mathrm{aA}$ \\
\hline & 58 & 0 & $\mathrm{cB}$ & 44 & $\mathrm{cA}$ & 47 & $\mathrm{bcA}$ & 44 & $\mathrm{aA}$ \\
\hline & 72 & 34 & $\mathrm{bB}$ & 45 & bcAB & 59 & $\mathrm{abA}$ & 57 & $\mathrm{aA}$ \\
\hline & 86 & 81 & $\mathrm{aA}$ & 59 & $a b c A B$ & 77 & $\mathrm{aA}$ & 52 & $\mathrm{aB}$ \\
\hline & 100 & 27 & $\mathrm{bC}$ & 74 & $\mathrm{aA}$ & 46 & $\mathrm{bcB}$ & 39 & $\mathrm{aBC}$ \\
\hline & 114 & 29 & $\mathrm{bB}$ & 70 & $a b A$ & 44 & $\mathrm{bcB}$ & 37 & $\mathrm{aB}$ \\
\hline & 128 & 37 & $\mathrm{bB}$ & 65 & abcA & 60 & $\mathrm{abA}$ & 52 & $\mathrm{aAB}$ \\
\hline & 142 & 52 & $\mathrm{bA}$ & 51 & abcA & 40 & bcA & 44 & $\mathrm{aA}$ \\
\hline $\mathrm{DMS}(\mathrm{E} \mathrm{d} . \mathrm{R})=$ & & \multicolumn{8}{|c|}{1,76} \\
\hline $\operatorname{DMS}(\mathrm{R}$ d. E $)=$ & & \multicolumn{8}{|c|}{1,46} \\
\hline C.V.(\%) & & \multicolumn{8}{|c|}{19,4} \\
\hline
\end{tabular}

Médias seguidas das mesmas letras, maiúsculas para linha e minúsculas para coluna, não diferem entre si, pelo teste de Tukey a 1\% de probabilidade. Valores transformados na fórmula $(\mathrm{x}+0,5)^{1 / 2} \mathrm{DAA}-$ dias após a antese 
O teor de água das sementes sem repouso foi máximo aos 30 dias após a antese $(82 \%)$, seguido por valor médio aos 44 dias (44\%), inferior aos 58 dias (24\%) e mínimo a partir de 72 dias entre 6 e $11 \%$ (Tabela 3). Assim, verificou-se que o tamanho é significativamente afetado pelo teor de água das sementes (Tabelas 2 e 3). Conforme Carvalho e Nakagawa (2000), o alto teor de água nos períodos iniciais de formação das sementes é necessário para que ocorra a translocação e a deposição do material fotossintetizado nos tecidos de reserva e, depois que a matéria seca é acumulada na semente, ocorre rápida desidratação. Neste estudo, isto ocorreu entre 58 e 72 dias após a antese (Tabela 3). Essa fase apresenta a duração variável de acordo com a espécie e condições climáticas, sendo, então, seguida de uma fase de rápida desidratação até oscilar com os valores de umidade relativa do ar, demonstrando que, a partir daquele ponto, a planta mãe não mais exerce controle sobre o teor de água da semente (RAGAGNIN; COSTA; HOPPE, 1994).

Após as diferentes condições de repouso, o teor de água das sementes sofreu decréscimos, de forma similar ao verificado para sementes de quiabeiro por Castro, Godoy e Cardoso (2008) e apresentou valores muito baixos, entre 4 e $7 \%$, em todas as épocas de colheita, podendo-se afirmar que o teor de água das sementes submetidas ao repouso não afetou o tamanho das sementes. Deve-se destacar que a partir dos 72 dias após a antese, as sementes apresentavam entre 6 e $11 \%$ de teor de água e puderam ser extraídas dos frutos com facilidade.

Os dados apresentados na Tabela 3 demonstram que as sementes colhidas aos 86 dias após a antese, sem repouso ou em repouso no fruto apresentaram maior emergência de plântulas em areia que as demais épocas de colheita e condições de repouso. $\mathrm{O}$ repouso da semente no racemo parece ter favorecido a capacidade de emergência de plântulas em areia, mesmo quando as sementes foram colhidas nas primeiras épocas, apresentando porcentagens máximas a partir dos 44 dias após a antese.
Assim, verificou-se que o repouso das sementes no racemo resultou em sementes com maior emergência de plântulas que a testemunha sem repouso, principalmente nas colheitas realizadas antes dos 100 dias após a antese. Também, para mamão, abóbora híbrida e quiabeiro o aumento do período de repouso dos frutos ocasionou melhoria da qualidade fisiológica das sementes (AROUCHA et al., 2005; COSTA; CARMONA; NASCIMENTO, 2006; CASTRO; GODOY; CARDOSO, 2008).

Deve-se ressaltar que os coeficientes de variação das características avaliadas nos frutos expressam a alta precisão do experimento, pois foram inferiores a $10 \%$ (Tabela 1), de modo semelhante aos valores obtidos para comprimento e largura de sementes (Tabela 2). Nas Tabelas 2 e 3, verificou-se que os demais coeficientes de variação das características das sementes e plântulas, de $10 \%$ a $20 \%$, podem ser considerados médios, implicando em boa precisão (PIMENTEL GOMES, 2000).

\section{Conclusão}

Os períodos de colheita e de repouso póscolheita afetam as características físicas de frutos e sementes de mamoneira AL Guarany 2002, mas nenhuma dessas características mostrou-se eficiente na identificação do ponto ideal de colheita, para a seleção de sementes com maior porcentagem de emergência de plântulas.

\section{Referências}

AGUiAR, I. B.; PERECIN, D.; KAGEYAMA, P. Y. Maturação fisiológica de sementes Eucalyptus grandis Hill ex Maiden. Instituto de Pesquisas e Estudos Florestais, Piracicaba, n. 38, p. 41-49, 1988.

ALVES, E. U.; SADER, R.; BRUNO, R. L A.; ALVES, A. U. Maturação fisiológica de sementes de sabiá. Revista Brasileira de Sementes, Brasília, v. 27, n. 1, p. 1-8, 2005.

AMARAL, J. G. C. Cultivo de mamona al guarany 2002. Disponível em: http://www.cati.sp.gov.br/ 
novacati/tecnologias/producao agricola/mamona/al guarany2002. htm> Acesso em: 17 jan. 2007.

AROUCHA, E. M. M.; SILVA, R. F.; OLIVEIRA, J. G.; VIANA, A. P.; GONZAGA, M. P. Época de colheita e período de repouso dos frutos de mamão (Carica papaya L.) cv. Golden na qualidade fisiológica das sementes. Ciência Rural, Santa Maria, v. 35, n. 3, p. 537-543, maio/ jun. 2005

BAHIA, H. F.; SILVA, S. A.; FERNANDEZ, L. G.; LEDO, C. A. S.; MOREIRA, R. F. C. Divergência genética entre cinco cultivares de mamoneira. Pesquisa Agropecuária Brasileira, Brasília, v. 43, n. 3, p. 357-362, 2008.

BARBOSA, J. M.; RODRIGUES, M. A.; PILIACKAS, J. M.; AGUIAR, I. B.; SANTOS JUNIOR, N. A. Maturação de sementes de Copaifera langsdorffii Desf. Revista do Instituto Florestal, São Paulo, v. 4, n. único, p. 665-674, 1992.

BRASIL. Ministério da Agricultura e Reforma Agrária. Secretaria Nacional de Defesa Agropecuária. Departamento Nacional de Defesa Vegetal. Coordenação de Laboratório Vegetal. Regras para análise de sementes. Brasília, 1992. 365 p.

CARVAlHO, N. M.; NAKAGAWA, J. Sementes: ciência, tecnologia e produção. 4. ed. Jaboticabal: Funep, 2000. 588 p.

COSTA, C. J.; CARMONA, R.; NASCIMENTO, W. M. Idade e tempo de armazenamento de frutos e qualidade fisiológica de sementes de abóbora híbrida. Revista Brasileira de Sementes, Brasília, v. 28, n. 1, p. 127-132, 2006.

CASTRO, M. M.; GOdOY, A. R.; CARDOSO, A. I. I. Qualidade de sementes de quiabeiro em função da idade e do repouso pós-colheita dos frutos. Ciência e agrotecnologia, Lavras, v. 32, n. 5, p. 1491-1495, 2008.

CROOKSTON, R. K.; HILL, D. S. A visual indicator of the physiological maturity of soybean seed. Crop Science, Madison, v. 18, n. 5, p. 867-870, 1978.

EMPRESA BRASILEIRA DE PESQUISA AGROPECUÁRIA - EMBRAPA. Centro Nacional de Pesquisa de Solos. Sistema brasileiro de classificação de solos. Brasília: EMBRAPA, 1999. 412 p.

FIGLIOLIA, M. B.; PIÑA-RODRIGUES, F. C. M. Manejo de sementes de espécies arbóreas. Instituto Florestal. Série Registros, São Paulo, n. 14, p. 1-56, 1995.

FIRMINO, J. L.; SANTOS, D. S. B.; SANTOS FILHO, B. G. Características físicas e fisiológicas de sementes de cerejeira (Torresia acreana Ducke) quando as sementes foram coletadas do chão ou do interior dos frutos. Revista Brasileira de Sementes, Brasília, v. 18, n. 1, p. 28-32, 1996.

FOWLER, J. A. P.; MARTINS, E. G. Coleta de sementes. In:__. Manejo de sementes de espécies florestais. Colombo: EMBRAPA Florestas, 2001. p. 9-13 (Documentos, 58).

LEONHARDT, C.; TILLMMANN, M. Â. A.; VILLELA, F. A.; MATTEI, V. L. Maturação fisiológica de sementes de tarumã-de-espinho (Citharexylum montevidense (Spreng.) Moldenke-Verbenaceae), no jardim botânico de Porto Alegre. Revista Brasileira de Sementes, Brasília, v. 23, n. 1, p. 100-107, 2001.

LOPES, J. C.; DIAS, P. C.; PEREIRA, M. D. Maturação fisiológica de sementes de quaresmeira. Pesquisa Agropecuária Brasileira, Brasília, v. 40, n. 8, p. 811-816, 2005.

OLIVEIRA, L. M.; CARVALHO, M. L. M.; CALDEIRA, C. M.; SILVA, C. D.; SILVA, D. G. Teste de tetrazólio em sementes de mamona. In: CONGRESSO BRASILEIRO DE MAMONA, 2., 2006, Aracaju. Resumos... Aracaju: EMBRAPA, 2006. Disponível em: <http://www.cnpa. embrapa.br/produtos/mamona/publicacoes/trabalhos cbm2/153.pdf>. Acesso em: 28 abr. 2008.

PIMENTEL GOMES, F. Curso de estatística experimental. 14. ed. Piracicaba: Nobel, 2000. 477 p.

RAGAGNIN, L. I. M.; COSTA, E. C.; HOPPE, J. M. Maturidade fisiológica de sementes de Podocarpus lambertii Klotzsch. Ciência Florestal, Santa Maria, v. 4, n. 1, p. 23-41, 1994.

SANTOS NETO, A. L.; SANTOS, D. C.; VILELA, F. L.; OLIVEIRA, L. M.; CARVALHO, M. L. M. Avaliação da qualidade de sementes de mamona classificadas em mesa densimétrica. In: CONGRESSO BRASILEIRO DE MAMONA, 2., 2006, Aracaju. Resumos... Aracaju: EMBRAPA, 2006. Disponível em: $<$ http://www.cnpa. embrapa.br/produtos/mamona/publicacoes/trabalhos cbm2/135.pdf $>$. Acesso em: 28 abr. 2008.

SAVY FILHO, A. Mamona: tecnologia agrícola. Campinas: Emopi, 2005. 105 p.

SILVA, S. D. A. Colheita. In: GOMES, J. C. C. Sistema de Produção da Mamona. Pelotas: Embrapa Clima Temperado, 2007. Disponível em: <http:// sistemasdeproducao.cnptia.embrapa.br/FontesHTML/ Mamona/SistemaProducaoMamona/colheita.htm>. Acesso em: 28 abr. 2008. 